\title{
Effect of $\gamma$-radiation sterilization on the stability of polyurethane potting compounds based on castor oil/SMDI and caprolactone polyol/SMDI, used for hollow fibre haemodialyzer
}

\author{
M JAYABALAN* and P P LIZYMOL \\ Polymer Division, Biomedical Technology Wing, Sree Chitra Tirunal Institute for Medical \\ Sciences and Technology, Thiruvananthapuram 695012 , India
}

MS received 30 August 1996; revised 31 May 1997

\begin{abstract}
Stability of polyurethane potting compounds based on castor oil/SMDI and caprolactone polyol/SMDI in repeated gamma radiation sterilization was studied. Radiationinduced degradation and leaching of low molecular weight fragments are higher in castor oil based polyurethane than in caprolactone polyol based polyurethane. For castor oil and caprolactone polyol based polyurethanes degradation increases up to $5 \mathrm{Mrad}$ dose of sterilization. Further increase of dose of sterilization decreases leaching in caprolactone polyol based polyurethane which has resulted from secondary reactions leading to crosslinking. In the case of castor oil based polyurethane such crosslinks undergo cleavage at $10 \mathrm{Mrad}$ dose of sterilization.
\end{abstract}

Keywords. $\gamma$-Radiation sterilization; hollow fibre: haemodialyzer; potting compound castor oil; caprolactone polyol; SMDI; polyurethane.

\section{Introduction}

Polyurethane is one of the widely used polymers in various biomedical applications such as artificial heart diaphrams, ventricular assist bladders, vascular grafts, mammery prostheses, pace maker lead insulators due to its excellent biocompatibility and wide range of physical and mechanical properties. Among all polyurethanes, linear segmented polyurethane based on diphenyl methane diisocyanate (MDI) is considered as more promising owing to the microphase segregation of soft and hard segments. However, degradation during processing and long-term implantation has been noticed by many investigators (Szycher et al 1983; Mazzu and Smith 1984). $\gamma$-Radiation sterilization and autoclaving are used to sterilize the polyurethane devices. Excessive and repeated sterilization will result in chain scission and formation of low molecular weight components such as methylene dianiline (MDA) (Mazzu and Smith 1984). Comparatively aliphatic polyurethanes are more stable under thermal conditions than aromatic polyurethanes. Therefore, polyurethanes based on dicyclohexyl methane diisocyanate (SMDI) were developed for various biomedical applications (Jayabalan et al 1991; Jayabalan and Rathinam 1992; Jayabalan and Shunmugakumar 1994; Shunmugakumar and Jayabalan 1992). In our previous study (Jayabalan and Lizymol 1995), SMDI based polyurethanes were developed as potential potting compound for the development of hollow fibre haemodialyzer. Effect of autoclaving sterilization on the stability of potting compound was studied. It was found that in the case of caprolactone polyol based polyurethane, autoclave sterilization with one cycle

\footnotetext{
* For correspondence
} 
may induce leaching of polyurethane fragments. It was found that up to 2 nd cycle sterilization, the decomposition of allophanate linkage leading to formation of urea linkage is increased for caprolactone polyol based polyurethane. Further increase in sterilization decreases the amount of urea formation which may be due to the non availability of allophanate group for further degradation (Jayabalan and Lizymol 1997). In the case of castor oil based polyurethane, the possibility of thermohydrolytic attack by autoclaving producing methanol-soluble and methanol-insoluble fragments in higher cycles of sterilization (Jayabalan and Lizymol 1995) is increased.

The present paper deals with the stability of the cured potting compound based on both castor oil/SMDI and caprolactone polyol/SMDI in repeated $\gamma$-radiation sterilization.

\section{Materials and methods}

Two polyurethane prepolymers were prepared using dicyclohexyl methane diisocyanate (SMDI) and castor oil and SMDI and polycaprolactone polyol with different $\mathrm{NCO} / \mathrm{OH}$ ratio. The prepolymers were analysed by UV spectrophotometry using a UV-160A Shimadzu Spectrophotometer. The setting time of the prepolymers was investigated using excess diisocyanate. The setting time was determined as per ASTM standard F 451-76. The composition which gives lowest setting time was used as potting compound. These prepolymers were cured using SMDI and the cured materials were characterized for thermal stability using a Dupont 990 Thermal Analyser by heating from ambient to $500^{\circ} \mathrm{C}$ at a rate of $10^{\circ} \mathrm{C} / \mathrm{min}$. Presence of residual isocyanate content was identified by infrared spectroscopy using a Perkin Elmer 597 IR Spectrophotometer. Spectrum was recorded using polyurethane film.

The stability of cured potting compound in $\gamma$-radiation sterilization was investigated by subjecting $1 \mathrm{~g}$ of the sample to repeated sterilization. Radiation dose of $2 \cdot 5,5 \cdot 0,7 \cdot 5$ and $10.0 \mathrm{Mrads}$ were used. The sterilized samples were immersed in $20 \mathrm{ml}$ methanol and kept at $40 \pm 2^{\circ} \mathrm{C}$ for a duration of 30 days. The methanol extract was subjected to vacuum evaporation using a rotary evaporater at $60^{\circ} \mathrm{C}$. The residue was redissolved in methanol using a definite quantity. The methanol solution was used for determination of low molecular weight compounds using the UV spectrophotometer. The stability of cured potting compound in hot methanol treatment was also investigated as control experiment.

\section{Results and discussion}

\subsection{Castor oil based polyurethane (SD/02)}

Infrared spectrum of cured $\mathrm{SD} / 02$ (figure 1a) shows the responses $3300 \mathrm{~cm}^{-1}(\mathrm{~N}-\mathrm{H}$ stretching hydrogen bonded), $1500 \mathrm{~cm}^{-1}\left(\mathrm{~N}-\mathrm{H}\right.$ bending) and $1710 \mathrm{~cm}^{-1}(\mathrm{C}=\mathrm{O}$ stretching hydrogen bonded) indicating the formation of polyurethane. The absence of peak at around $2250 \mathrm{~cm}^{-1}$ indicate the absence of unreacted isocyanate in the cured polyurethane. The absence of peaks at around $1732 \mathrm{~cm}^{-1}$ for free $\mathrm{C}=\mathrm{O}$ stretching and at around $3450 \mathrm{~cm}^{-1}$ for free $\mathrm{N}-\mathrm{H}$ stretching indicate the formation of hydrogen bonding in the cured polyurethane (David and Stakey 1969). The formation of 
$\gamma$-radiation sterilization on stability of polyurethane compounds

729

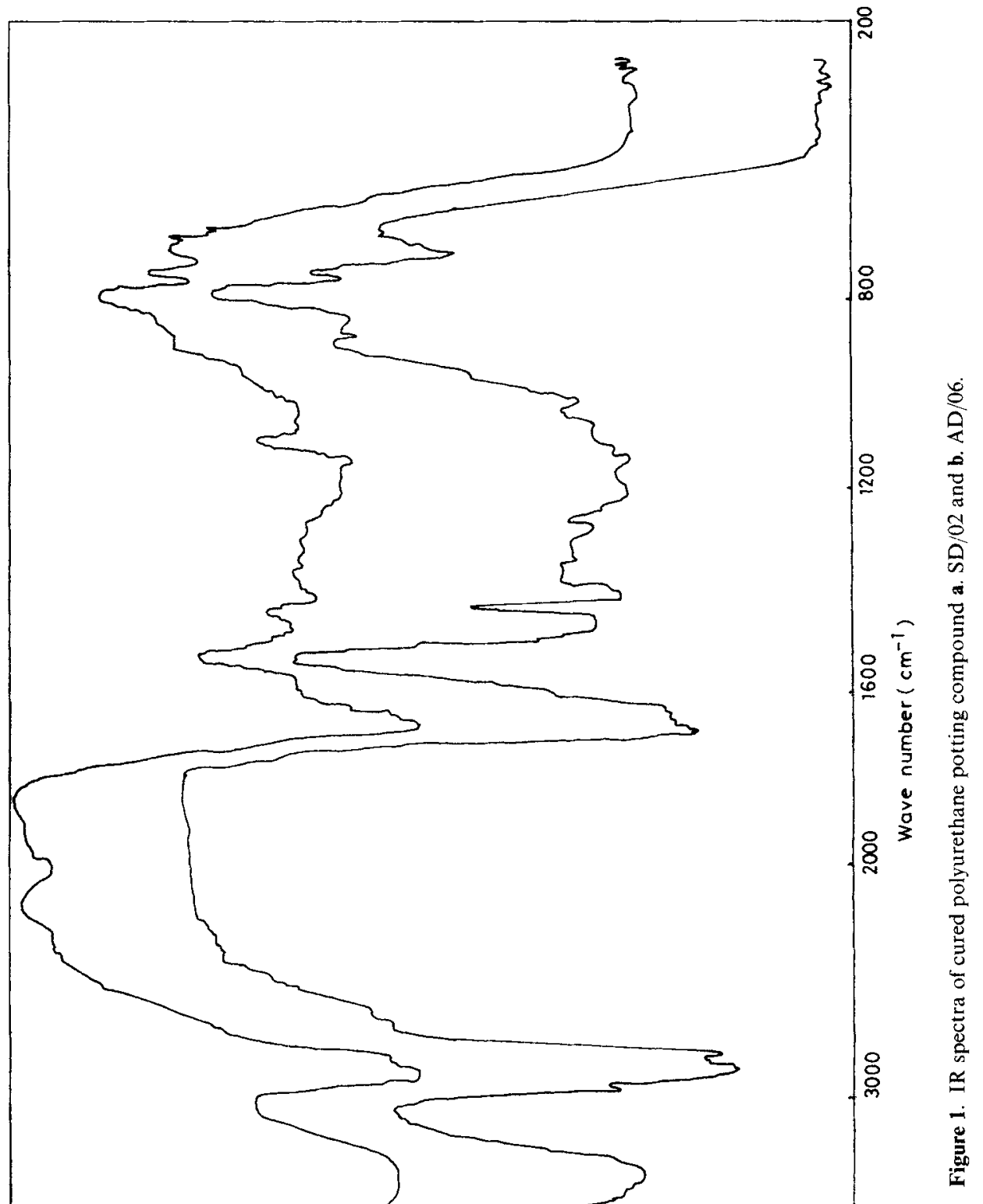

(Inn K101!!910) 22001!usuo11 


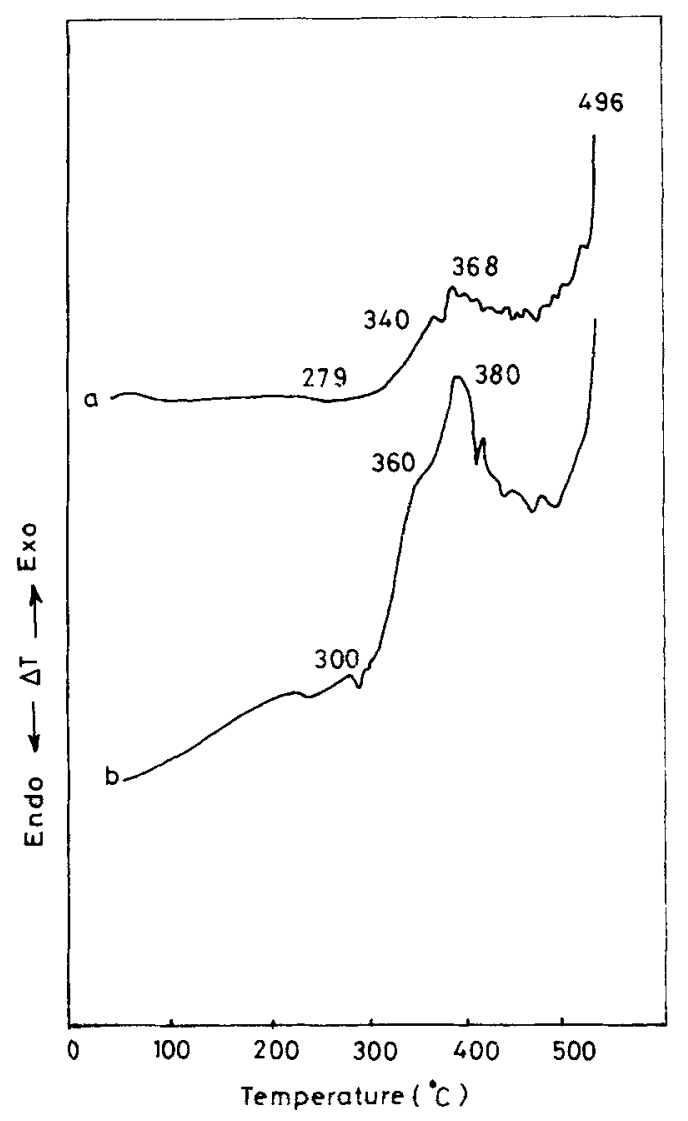

Figure 2. DTA thermogram of cured and untreated polyurethane $\mathbf{a} . \mathrm{AD} / 06$ and b. SD/02.

hydrogen bonds is ascertained with the appearance of a band centred at $3300 \mathrm{~cm}^{-1}$ for hydrogen bonded $\mathrm{N}-\mathrm{H}$ stretching and multiple peaks around $1680 \mathrm{~cm}^{-1}$ for bonded $\mathrm{C}=\mathrm{O}$ stretching. The shift of $\mathrm{N}-\mathrm{H}$ stretching peak for $150 \mathrm{~cm}^{-1}$ indicated moderate degree of hydrogen bonding as reported by Kontou et al (1990).

The differential thermogram of cured SD/02 (figure 2a) showed a weak endotherm at $300^{\circ} \mathrm{C}$ which may possibly be due to softening by weakening of feeble physical crosslinks such as hydrogen bonds (a virtually crosslinked structure) in some domains. The weak endotherm at $360^{\circ} \mathrm{C}$ is probably due to chain scission at chain ends. The exotherm at $380^{\circ} \mathrm{C}$ is due to condensation through newly formed chain ends.

Figure $3 \mathrm{a}$ is the UV spectrum of prepolymer (component $\mathrm{A}$ ) of $\mathrm{SD} / 02$. The major absorption peak is at about $246 \mathrm{~nm}$.

The extent of radiation-induced degradation and leaching of low molecular weight fractions could be gauged from the absorbance data (table 1 and figure 4) observed for the single major peak at around $226 \mathrm{~nm}$. Comparison of figures $3 \mathrm{a}$ and 4 reveals that the component leached in methanol from sterilized samples is not the prepolymer (component 1), but some other degraded methanol-soluble fragment. With increase of radiation dose up to $5 \mathrm{Mrad}$ and then from 7.5 to $10 \mathrm{Mrad}$ the polyurethane undergoes degradation when compared with control methanol treatment alone. From table 1 and 


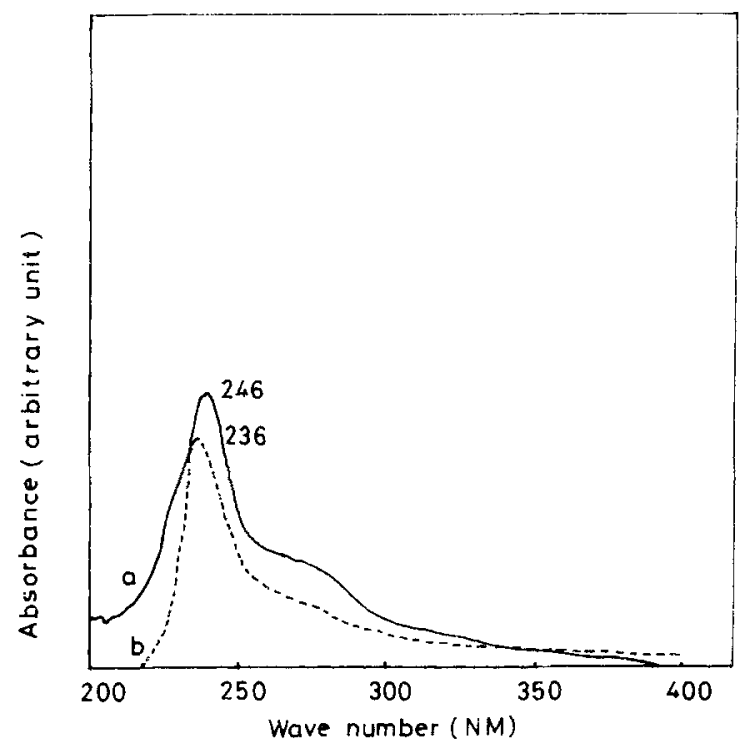

Figure 3. UV spectra of prepolymers (component l) a. SD/02 and b. AD/06.

Table 1. Absorbance of methanol extract from $1 \mathrm{~g}$ of the cured $\mathrm{SD} / 02$ sample after $\gamma$-radiation sterilization.

\begin{tabular}{lll}
\hline Sample & Dose (Mrad) & $\begin{array}{l}\text { Absorbance for methanol- } \\
\text { soluble fraction from lg of } \\
\text { the sample at about } 226 \mathrm{~nm}\end{array}$ \\
\hline $\begin{array}{l}\text { Control } \\
\text { SD } 02\end{array}$ & 0 & $80 \cdot 35$ \\
Test & 2.5 & 449.09 \\
SD/02 & & 542.54 \\
SD/02 & 5 & $452 \cdot 215$ \\
SD $/ 02$ & 7.5 & 647.98 \\
SD $/ 02$ & 10 & \\
\hline
\end{tabular}

figure 4 it is observed that methanol induces degradation during extraction. Methanol induces hydrolytic degradation at urethane linkage and also leaching of low molecular weight components (Bruck 1980). The increased leaching in radiation-sterilized polyurethane samples up to $5 \mathrm{Mrad}$ may be due to the enhancement in degradation of urethane linkage by radiation. Further increase of radiation dose results in secondary reactions resulting in the formation of allophanate linkage. The degradation of urethane linkage may lead to formation of methylene dicyclohexylamine. The possibility of simultaneous cleavage at two successive urethane linkages to form amine is rare (Shintani and Nakamura 1991). Abundant terminal amino groups in the potting materials compared with thermoplastic polyurethane may be available (Shintani and Nakamura 1989) due to insufficient curing. Therefore, these polyurethane chain ends are more prone to formation of amine upon radiation as shown in figure 5 . However the amine was not detected with the present samples. This is because isocyanate reacts 


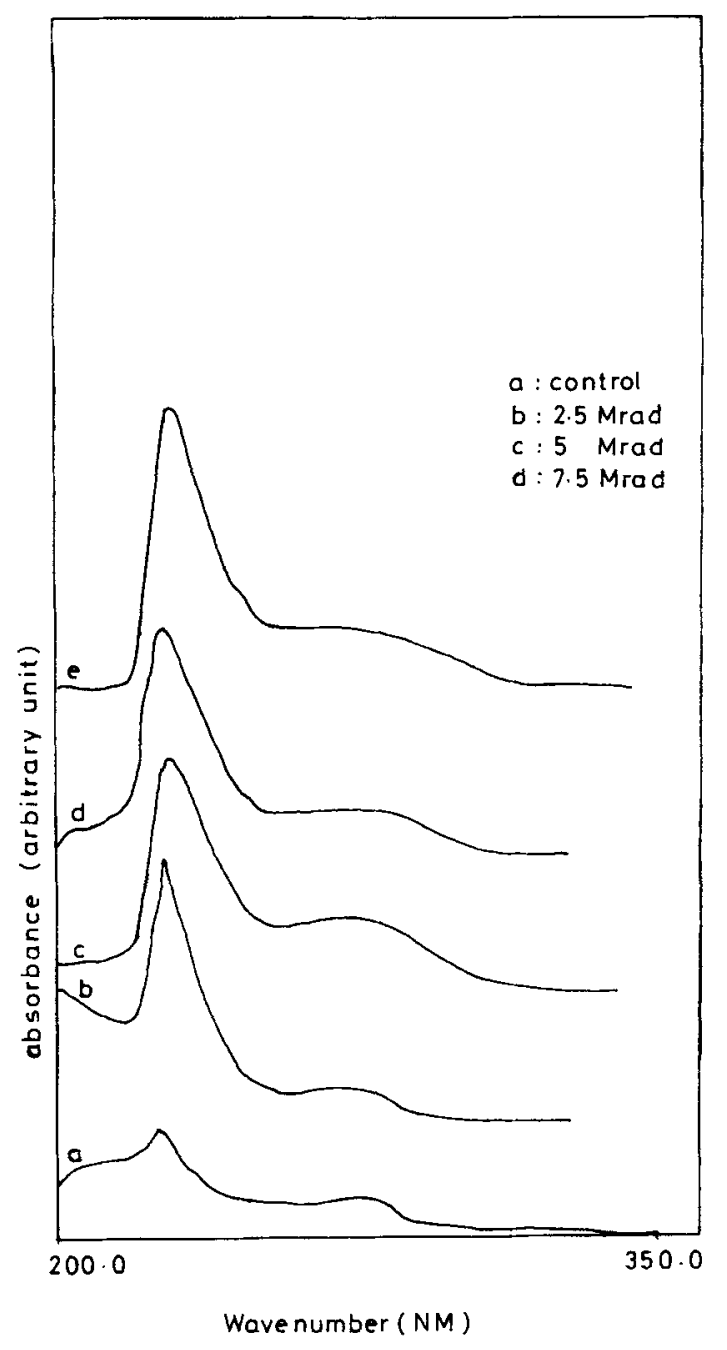

Figure 4. UV spectrum of methanol extract of SD/02 potting compound.

to form allophanate instead of forming just amine. The formation of allophanate linkage may be the reason for the comparatively less intensity of absorption at 7.5 Mrad. On further increase of radiation dose up to $10 \mathrm{Mrad}$, allophanate linkage undergoes breaking down resulting in a higher intensity of absorption than the preceding one. From the observations it can be concluded that radiation sterilization of castor oil based polyurethane potting compound induces degradation and leaching of low molecular weight components other than diamines.

\subsection{Caprolactone polyol based polyurethane ( $A D / 06)$}

Figure $1 \mathrm{~b}$ shows the infrared spectrum of cured and control $\mathrm{AD} / 06(1 \cdot 15)$ from which we can find the absence of unreacted isocyanate with the absence of peak at $2250 \mathrm{~cm}^{-1}$. The presence of peak at $3300 \mathrm{~cm}^{-1}\left(\mathrm{~N}-\mathrm{H}\right.$ stretching $\mathrm{H}$-bonded) and $1710 \mathrm{~cm}^{-1}$ 
(i) A mine formation

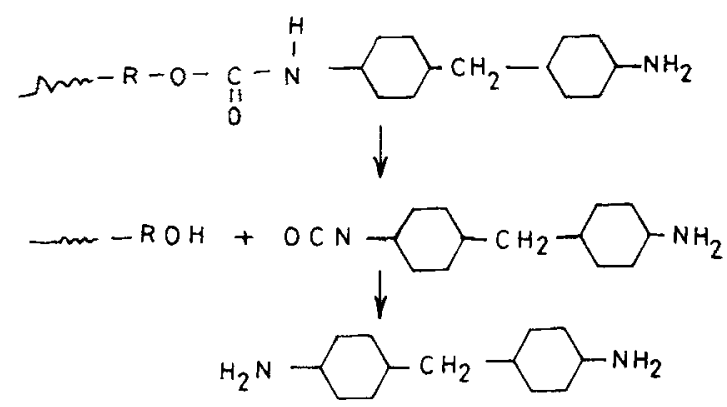

(ii) Allophanate formation

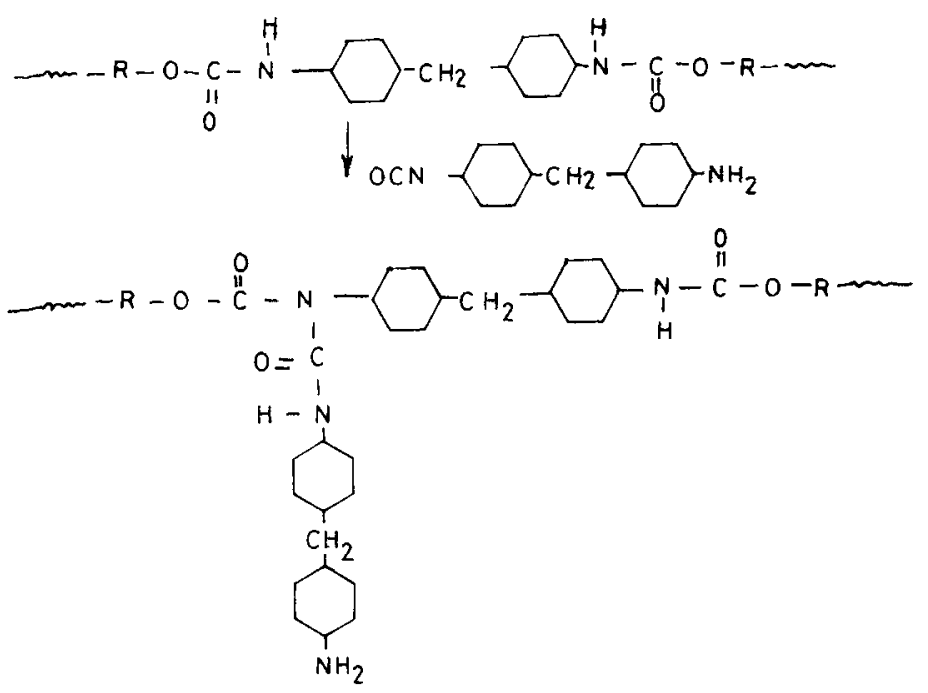

Figure 5. Formation of diamine and allophanate linkages.

Table 2. Absorbance of methanol extract of $1 \mathrm{~g}$ of the cured Ad/06 sample after $\gamma$-radiation sterilization.

\begin{tabular}{lll}
\hline Sample & Dose & $\begin{array}{l}\text { Absorbance for methanol- } \\
\text { soluble fraction from I g of } \\
\text { the sample at about } 226 \mathrm{~nm}\end{array}$ \\
\hline AD/06 & 0 & 80.975 \\
Control & & \\
Test & & \\
AD $/ 06$ & 2.5 & 223.58 \\
AD $/ 06$ & 5 & 273.57 \\
AD $/ 06$ & 7.5 & 269.82 \\
AD $/ 06$ & 10 & 100.29 \\
\hline
\end{tabular}

( $\mathrm{C}=\mathrm{O}$ stretching $\mathrm{H}$-bonded $)$ indicates the formation of polyurethane. Absence of peak at $1732 \mathrm{~cm}^{-1}$ for the $\mathrm{C}=\mathrm{O}$ stretching and at around $3450 \mathrm{~cm}^{-1}$ for free $\mathrm{N}-\mathrm{H}$ stretching indicate the formation of hydrogen bond in the cured polyurethane (David and Stakey 1969). The formation of hydrogen bonds is ascertained with appearance of broad band centring at $3300 \mathrm{~cm}^{-1}$ for bonded $\mathrm{N}-\mathrm{H}$ stretching and shoulder at 
$1660 \mathrm{~cm}^{-1}$ for bonded $\mathrm{C}=\mathrm{O}$ stretching $1710 \mathrm{~cm}^{-1}$ as in the case of $\mathrm{SD} / 02$ system indicating moderate degree of hydrogen bonding.

The differential thermogram (figure $2 b$ ) of the potting compound showed a weak endotherm at $279^{\circ} \mathrm{C}$ which may possibly be due to softening by cleavage of feeble physical crosslinks such as hydrogen bonds (a virtually crosslinked structure) in some domain. Two exotherms are visible at $340^{\circ} \mathrm{C}$ and $368^{\circ} \mathrm{C}$. They may be due to condensation through newly formed chain ends. Figure $3 \mathrm{~b}$ is the UV spectrum of prepolymer (component $\mathrm{A}$ ) of $\mathrm{AD} / 06$. The spectrum shows a prominent absorption peak at $236 \mathrm{~nm}$. Comparison of tables 1 and 2 shows that the effect of radiation on degradation is less in the case of caprolactone polyol based polyurethane compared to castor oil based polyurethane. The degradation on polyurethane linkage of both castor oil based polyurethane and caprolactone based polyurethane by methanol are almost same. Moreover, the intensity of absorption in sterilized samples (figure 6) increases up to $5 \mathrm{Mrad}$ and then decreases with further increase in radiation dose. UV spectra of methanol extract of sterilized samples (figure 6) and prepolymer (figure $3 b$ ) gives absorbance at two different wave numbers. This shows that component leached from cured polyurethane is not the prepolymer but some other fragment as in the case of $\mathrm{SD} / 02$. Up to $5 \mathrm{Mrad}$ sterilization may induce degradation of urethane linkage and leaching of low molecular weight fractions as in the case of castor oil based

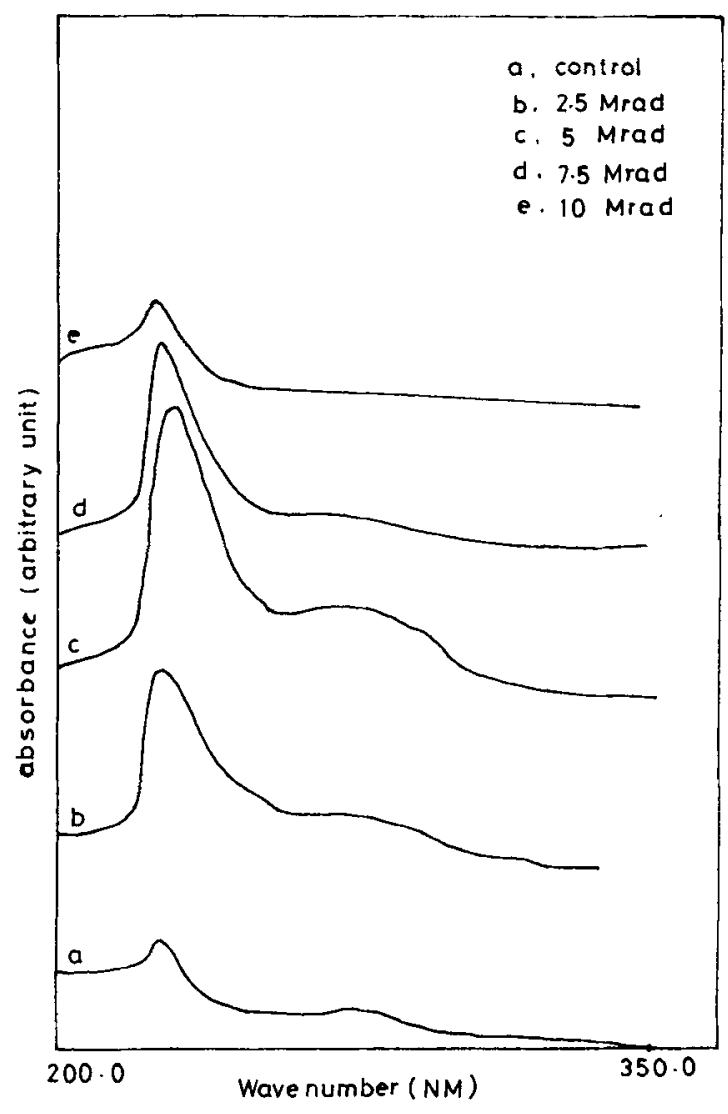

Figure 6. UV spectrum of methanol extract of sterilized AD/06 potting compound. 
polyurethane but to a lesser extent. On further increasing the radiation dose the intensity of absorption decreases. At higher radiation doses secondary reactions may occur resulting in crosslinking and formation of allophanate linkage (as shown in figure 5) thereby decreasing the extent of leaching.

In the case of both castor oil and caprolactone based polyurethane, radiation sterilization induces degradation and crosslinking though no amine product was detected in sterilized samples. Degradation is more for castor oil based polyurethane with increased dose of radiation. On the other hand degradation is getting reduced with increased dose of radiation in the case of caprolactone polyol based polyurethane.

\section{Acknowledgements}

The authors acknowledge Director, SCTIMST, Thiruvananthapuram and Head, B.M.T. Wing, SCTIMST for supporting Haemodialyzer programme under which this work was carried out. The analytical help provided by Dr K Sreenivasan and $\mathrm{Mr}$ Willey Paul is also acknowledged.

\section{References}

Bruck S D 1980 Properties of biomaterials in physiological environment (Boca Raton, Florida: C.R.C. Press) p. 76

David D J and Stakey B B 1969 Analytical chemistry of polyurethane (New York: Wiley Interscience) Jayabalan M and Rathinam K 1992 Clinic al Mater. 11179

Jayabalan M and Shunmugakumar N 1994 Med. Prog. Through Tech. 20201

Jayabalan M and Lizymol P P 1995 Macromolecules-Current trends (ed.) S Venkatachalam (New Delhi: Allied Pub.) 21136

Jayabalan M and Lizymol P P 1997 J. Polym. Mater. 1449

Jayabalan M, Shunmugakumar N, Rathinam K and Kumari T V 1991 J. Biomed. Mater. Res. 251431

Kontou E, Spathis G, Niaounakis M and Kefalas V 1990 Colloid. Polym. Sci. 268639

Mazzu A and Smith C P 1984 J. Biomed. Mater. 18961

Shunmugakumar N and Jayabalan M 1992 Artif. Organs 16256

Shintani H and Nakamura A 1989 J. Anal. Toxicol. 13354

Shintani H and Nakamura A 1991 J. Appl. Polym. Sci. 421979

Szycher M, Poirier V C and Demsey D T 1983 J. Elastomer Plast. 1581 